\title{
Predictive role of $\alpha v \beta 3$ integrin, and VEGF in colorectal adenocarcinoma progression in Iraqi patients
}

\author{
Ibrahim AbdulmajeedAltamemi ${ }^{1}$, Alaa Ghani Hussein ${ }^{2}$, Ahmed Raheem Rayshan $^{3}$ \\ ${ }^{1}$ Deparment of Medical microbiology, College of medicine, Al-Qadisiya University, Alqadisia, Iraq \\ ${ }^{2}$ Department of Pathology, College of medicine, Alnahrain University, Baghdad, Iraq \\ ${ }^{3}$ Deparment of Pathology, College of medicine, Al-Qadisiya University, Alqadisia, Iraq
}

Email Address:

Ibrahim.altamemi@gmail.com(I. A. Altamemi)

\section{To cite this article:}

Ibrahim Abdulmajeed Altamemi, Alaa Ghani Hussein, Ahmed Raheem Rayshan. Predictive Role of $\alpha$ V $\beta 3$ Integrin, and VEGF in Colorectal Adenocarcinoma Progression in Iraqi Patients. Cancer Research Journal. Vol. 1, No. 3, 2013, pp. 26-30.

doi: $10.11648 /$ j.crj.20130103.11

\begin{abstract}
Angiogenesis, the formation of new blood vessels from pre-existing ones, is enhanced in various pathological conditions including rheumatoid arthritis, diabetic retinopathy, and cancer development. Angiogenic processes are regulated by both growth factors, such as vascular endothelial growth factor (VEGF), and adhesion molecules, such as integrin. Understanding the molecular mechanisms that underlieregulation of angiogenesis especially VEGF function, is essential for the development of safe and effective antiangiogenic therapies. Thus, current study was aimedto investigate predictive role of $\beta 3$ integrin and vascular endothelial growth factor (VEGF) protein expression in colorectal adenocarcinoma sample from Iraqi patients, through linking its expression with tumor histopathological variables (stage, grade, grade, andlymph node involvement), by using Immunohistochemicalstaining method. Study done on 35 colorectal cancer samples and their respective resection margins.Present study demonstrated that, the positive expression rate of integrin $\beta 3$ and VEGF in non-tumorcolorectal mucosa $(25.33333 \pm 1.974842$, and $32.4 \pm 1.974842)$ was significantly lower than that of the colorectal cancer (CRC)tissue $(76.47059 \pm 2.878562$, and 79.45714 $\pm 2.293705 ; \mathrm{P}<0.05)$. Moreover, when CRC samples breakdown according to histopathological variables, In patients of stage C-D, poorly differentiated, and withlymph node (L.N)invasion, the positive expression rates of integrin $\beta 3$ were significantly higher than those in patients of patients with stage A,B, well or moderately differentiated, and without lymphatic metastasis $(P<0.05, P<0.05$, and $P<$ $0.05 ; P<0.05, P<0.05$, and $P<0.05$ ), respectively. In conclusion Integrin $\beta 3$ and VEGF expression can synergistically enhance tumor angiogenesis, and may play a crucial role in invasion and metastasis of colorectal carcinoma. Therefore, they may be prognostic biomarkers and novel molecular therapeutic targets.
\end{abstract}

Keyword: Colorectal Cancer, Angiogenesis, VEGF

\section{Introduction}

Angiogenesis is the formation of new capillaries from preexisting vessels, it is essential for several normal physiological events such as embryonic vascular development, wound healing, and reproduction. It is also involved in pathological processes, including tumor growth, diabetic microvascular disease, and rheumatoid arthritis [1, 2]. Angiogenesis depends on input from growth factors and vascular cell adhesion signals [3, 4]. Among angiogenic growth factors and adhesion molecules, are vascular endothelial cell growth factor-A (VEGF-A) and $\alpha v \beta 3$ integrin, respectively, are two well-established representatives. To date, VEGF-A is the only growth factor proven to be specific and critical for blood vessel formation $[5,6]$. Integrin are transmembrane glycoproteins composed of non-covalently associated $\alpha$ - and $\beta$-chains which recognize proteins of the extracellular matrix (ECM).The importance of $\alpha \mathrm{v} \beta 3$ in angiogenesis has been underscored based on the findings that $\alpha \mathrm{v} \beta 3$ is prominently expressed on the surfaces of endothelial cells and is highly upregulated on angiogenic blood vessels such as those in solid tumors and in granulation tissue at the base of healing wounds [7].Recent investigations have shown that high expression of integrin $\beta 3$ is positively correlated with invasion and metastasis of cancer cells and tumor angiogenesis [8, 9], but only a few studies have investigated the relationship between integrin $\beta 3$ and 
prognosis of colon cancer.The molecular mechanisms by which colorectal cancer cells exploit the hepatic microenvironment for selective growth and survival remain obscure. The report by Conti et al. has now identified essential functions for $\alpha v \beta 3$ integrin in promoting metastatic colorectal adenocarcinoma cell growth and survival in the liver [10]. In our study, we aimed to evaluate integrin $\beta 3$ and vascular endothelial growth factor (VEGF) protein expression in colorectaladenocarcinoma (CRC). And its relationship to pathological parameters such as tumor stage, grade, and lymph node infiltration.

\section{Materials and Methods}

\subsection{Patients and Sampling}

Thirty five patients with colorectal adenocarcinoma, who were confirmed histopathologicaly, were included in this study. Their age were ranged from 20- 80 years. Paraffin embedded blocks of tumor and resection margins were retrieved along with the histopathological report of each patient from histopathological laboratory. For staging of the cancer, astler-coller staging system was adopted in this study [11]. In addition, resection margins were confirmed again to be free of malignancy. Adequate thin paraffin embedded sections $(5 \mu \mathrm{m}$ thick) of tumor and resection margins were prepared on positively charged slides for the immunohistochimistrey Technique (IHC).

\subsection{Immunohistochemical Detection of $\alpha$ v 3 Integrin, and VEGF}

A primary monoclonal antibody against" $\alpha$ v $\beta 3$ integrin, and VEGF"(US biological, USA) reacts with their antigen. Biotinylated secondary antibody then reacts with the primary antibody. This is followed by the attachment of an enzyme-conjugated streptavidin to the biotins on the secondary antibody. The enzyme converts a substrate to a colored reaction product. And the procedure has been done according to manufacture instructions (US biological, USA).There after slides were examined by histopathologist under light microscope (100x).

\section{Results}

\subsection{Histopathological Data}

Thirty five patients with colorectal adenocarcinoma were investigated. According to the histological differentiation, tumors were broken down in to three groups, well differentiated ( $\mathrm{WD}, \mathrm{n}=7$ ), moderately differentiated (MD, $\mathrm{n}=20)$, and poorly differentiated $(\mathrm{PD}, \mathrm{n}=8)$, moreover, patients were further grouped according to their histopathological criteria, as follow: tumor stage (A, $n=6, B$, $\mathrm{n}=10, \mathrm{C}, \mathrm{n}=11$, and $\mathrm{D}, \mathrm{n}=8$ ), lymph node involvement (free, $\mathrm{n}=16$, and involved, $\mathrm{n}=19$ ).

\subsection{Tumor Sites versus Resection Margins}

Based on immunohistochemical staining method, and according to statistical analysis there were significant difference based on mean \pm standard error (SE) of both $\alpha v \beta 3$ integrin, and VEGF protein expression between tumor sites and their resection margins (55.25 $\pm 4.1,19.2 \pm 2.31$; $\mathrm{p}<0.001$ and, 79.45714 $\pm 2.293705,32.4 \pm 1.974842 ;$; $\mathrm{p}<0.001$ respectively),(table 1 ). A noteworthy here is that high intensity of staining is found in the periphery of necrotic foci of the colorectal cancer, labeling with the VEGF antibody distinctly intensified in tumor epithelium adjacent to the necrotic foci. Moreover, the tumor stroma cells also labeled for VEGF, labeled stromal cells included fibroblasts and smooth muscle cells. $\alpha v \beta 3$ and VEGF IHC staining in tumor sample and resection margin are shown in figure 1 .

Table 1. $\alpha v \beta 3$ integrin, and VEGF protein expression in tumor sites and their resection margins, based on t.Test

\begin{tabular}{lcll}
\hline Sample & \multirow{2}{*}{ No. } & $\begin{array}{l}\boldsymbol{\alpha v \beta 3} \\
\text { Mean } \pm \text { SE }\end{array}$ & $\begin{array}{l}\text { VEGF } \\
\text { Mean } \pm \text { SE }\end{array}$ \\
\hline Normal & 35 & $25.33333 \pm 1.974842$ & $32.4 \pm 1.974842$ \\
Tumor & 35 & $76.47059 \pm 2.878562$ & $79.45714 \pm 2.293705$ \\
* $(\mathbf{P}<\mathbf{0 . 0 0 5})$. & & $*(\mathbf{P}<\mathbf{0 . 0 0 5})$. \\
\hline
\end{tabular}

\subsection{Correlation among Protein Expression of $\alpha v \beta 3$ and VGF with Different Histopathological Variables}

$\alpha \mathrm{v} \beta 3$ and VEGF protein expression in colorectal adenocarcinoma were analyzed against the different histopathological features of the tumors based on Spearman's correlation. As shown in Table 2, and 3, current study demonstrated that there were significant correlations between both $\alpha v \beta 3$ and VEGF expression with tumor stage, and grade depending on mean expression \pm SE value $(P<$ $0.05, P<0.05 P<0.05$, and $P<0.05$ respectively). Moreover, a significant differences were found when we compare the expression level of both markers according to L.N involvement $(\mathrm{P}<0.05, \mathrm{P}<0.05$ respectively) table 4 .

Table 2. Expression pattern of $\alpha v \beta 3$ and VEGF along with tumor stage of $C R C$, based on spearman's correlation $\left(r_{s}\right)$

\begin{tabular}{llll}
\hline Stage & No. & $\begin{array}{l}\text { Mean } \pm \text { SE } \\
\boldsymbol{\alpha v \beta 3}\end{array}$ & VEGF \\
\hline A & 6 & $51.33 \pm 2.33$ & $59.00 \pm 4.80$ \\
B & 10 & $67.60 \pm 2.67$ & $75.00 \pm 2.15$ \\
C & 11 & $85.45 \pm 2.01$ & $84.27 \pm 1.82$ \\
D & 8 & $96.50 \pm 0.68$ & $93.75 \pm 1.84$ \\
LSD value & --- & $6.428 *$ & $7.334 *$ \\
$*(\mathbf{P}<\mathbf{0 . 0 5})$. & & & \\
\hline
\end{tabular}

Table 3. Expression pattern of $\alpha v \beta 3$ and VEGF along with tumor grade of $C R C$, based on spearman's correlation $\left(r_{s}\right)$

\begin{tabular}{llll}
\hline Grade & No. & $\begin{array}{l}\text { Mean } \pm \text { SE } \\
\boldsymbol{\alpha v \beta 3}\end{array}$ & VEGF \\
\hline WD & 6 & $52.80 \pm 4.57$ & $60.67 \pm 5.53$ \\
MD & 19 & $74.47 \pm 3.18$ & $78.26 \pm 1.76$ \\
PD & 10 & $92.85 \pm 2.84$ & $93.00 \pm 1.80$ \\
LSD value & --- & $12.935 *$ & $7.934 *$ \\
* (P<0.05). & & & \\
\hline
\end{tabular}


Table 4. Expression pattern of $\alpha v \beta 3$ and VEGF along with L.N involvement of CRC, based on spearman's correlation $\left(r_{s}\right)$

\begin{tabular}{llll}
\hline LN & No. & $\begin{array}{l}\text { Mean } \pm \text { SE } \\
\boldsymbol{\alpha v \beta 3}\end{array}$ & VEGF \\
\hline Free & 16 & $64.90 \pm 3.85$ & $69.00 \pm 2.93$ \\
Involved & 19 & $90.11 \pm 1.74$ & $88.26 \pm 1.68$ \\
LSD value & --- & $10.391 *$ & $5.066^{*}$ \\
$*(\mathbf{P}<\mathbf{0 . 0 5})$. & & & \\
\hline
\end{tabular}
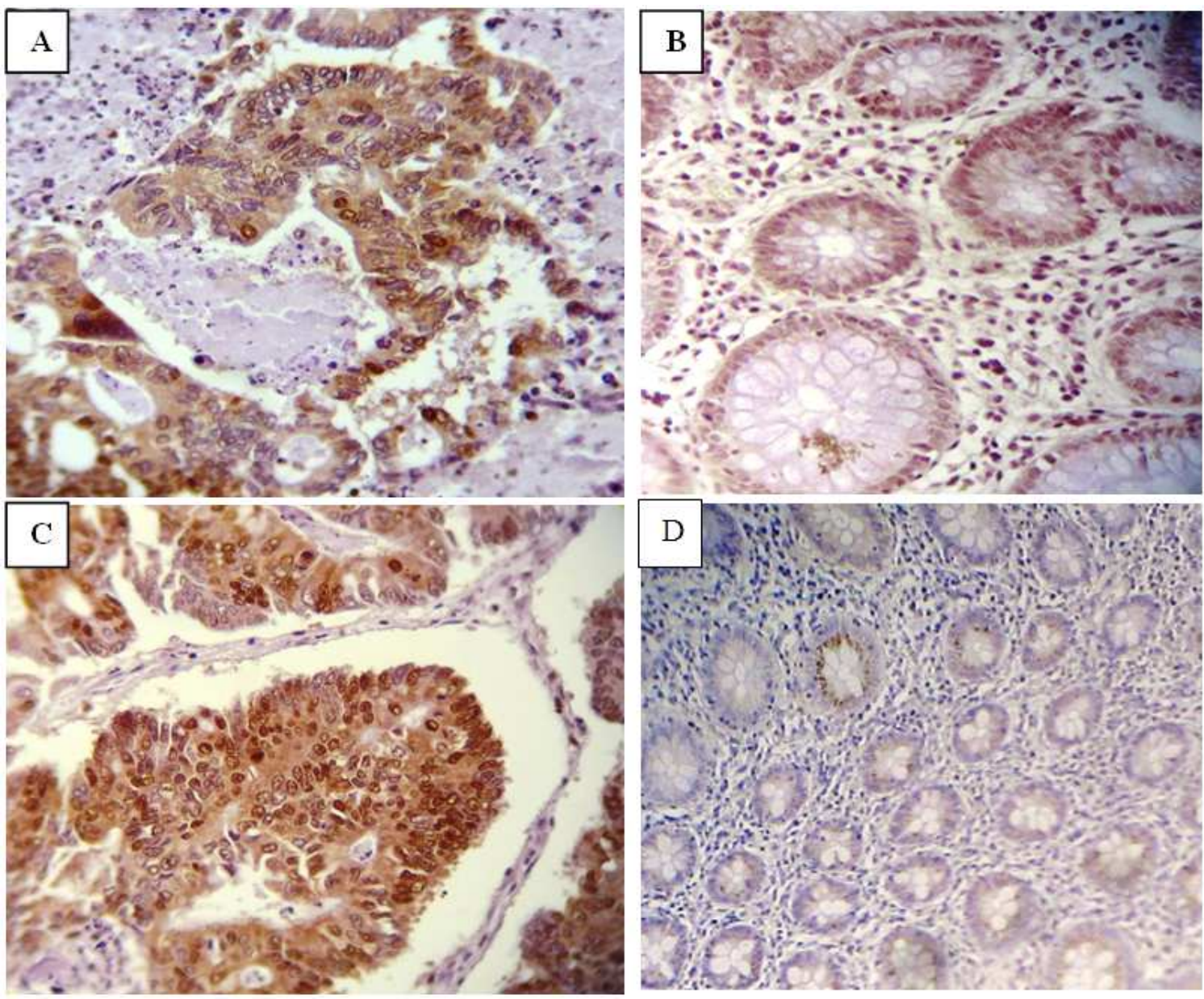

Figure1. Immunohistochemichal staining of $\alpha v \beta 3$, and VEGF in colorectal adenocarcinoma section and their resection margins by DAP (brown color) counterstained with hematoxylin. (A) $\alpha v \beta 3$ protein expression in tumor cells. (B) Resection margin stained with $\alpha v \beta 3 i n t e g r i n .(C)$ VEGF expression in tumor section. (D) Resection margin stained with VEGF. Magnification power (400X).

\section{Discussion}

Since, current clinical methods can not accurately predict which patients will develop metastasis. Thus, to develop effective new strategies for the prediction, diagnosis and treatment of cancer patients, the molecular mechanisms controlling tumor aggressiveness must be identified. Therefore, Integrin and VEGF could be one of such mechanisms. Integrin $\beta 3$ may enable VEGF to stimulate endothelial cell proliferation and capillary angiogenesis through activating VEGF receptor-2 (Flk-1) and VEGF receptor-3 (Flt-4) [12, 13].Current study had demonstrated a significant over expression of $\alpha \mathrm{v} \beta 3$, and VEGF protein expression in tumor tissue in compares with their resection margins $(\mathrm{p}<0.05$, and $\mathrm{p}<0.05$ respectively, table 1$)$. This observation came in compatible with previous studies that focused on VEGF in colorectal and other tumors since; they illustrated a significant increase in VEGF protein expression with respect to tumor status, nodal metastasis, and with poor clinical outcome[14]. Moreover, current results solidify previously published data which mentioned that $\alpha v \beta 3$ is positively correlated with angiogenic activity, invasion, and metastasis, [15]thus, it consider the leading edge of liver metastasis.Since, hypoxia is an important stimulus for mediating VEGF mRNA cellular expression during angiogenic response $[16,17]$ and the current data demonstrated an increase of VEGF expression around necrotic tissue. Thus, it would be acceptable to anticipate 
that hypoxia could have the upper hand behind this current outcome. Moreover, current study showed that integrin $\beta 3$ and VEGF protein expression rate were significantly associated with tumor stage, poor differentiation, and lymphoid node invasion, $(P<0.05, \quad P<0.05 \& P<$ 0.05 respectively; able $2,3, \& 4)$. Thus, it came with previous studies; they mentioned that an over expression of $\beta 3$ integrin generally appears to be positively correlated with tumorigenicity. For example, expression of the $\beta 3$ integrin subunit in melanoma in situ has been found to correlate with tumor thickness, the ability to invade and metastasize, and poor prognosis [18].Also, increased expression of integrin $\beta 3$ in gastric cancer influenced the adhesion between tumor cells and ECM. $\beta 3$ integrinmay influence signal transduction, thereby changing the biological behavior of tumor cells, and enhancing the potency of infiltration and migration [19]. Since, Angiogenesis not only accelerates tumor growth, but also increases the opportunity of tumor cells for invading the vasculature, hence it promotes tumor metastasis. Thus, that could explain higher VEGF expression at the invasive tumor edge and strong association with L.N metastasis. As the bridge between vascular endothelial cells and ECM, integrin play an important role in angiogenesis [20].Previous studies have shown that integrin $\alpha v \beta 3$ is minimally expressed on resting or normal blood vessels, but is significantly up-regulated in vascular cells within human tumors, and has been implicated in tumor-induced angiogenesis[21,22]. Unligated integrin can act as a negative regulator of cell survival, initiating a process of "integrin mediated death" [23]. In our assay system, $\beta 3$ integrin are presumably in an activated state because of VEGF-A released from the tumor cells. Evidence suggests that integrinmay associate with a number of immobilized pro-angiogenic molecules. $\beta 3$ integrin may interact with distinct isoforms of VEGF-A and these interactions may enhance endothelial cell adhesion, migration and survival $[24,25]$.In addition to interactions with secreted and matrix bound growth factors, integrin also associate with growth factor receptors. VEGF-A-mediated activation of VEGFR2 recruits Src and facilitates phosphorylation of the $\beta 3$ cytoplasmic tail [26]. The phosphorylated $\beta 3$ tail may promote interactions between $\alpha v \beta 3$ and VEGFR2, thereby enhancing endothelial proliferation and survival [26]. Finally, further studies based on pre-malignant, and linking expression level of VEGF with microvascular density are needed to improve current results.

\section{Conclusion}

In summary, integrin $\beta 3$ and VEGF are consideringa guide marker which synergistically enhance tumor angiogenesis, and may play crucial roles in invasion and metastasis of CRC. Therefore, they can be used as biomarkers for diagnosis and prognosis, and as novel molecular therapeutic targets.

\section{References}

[1] Risau, W. (1997) Mechanisms of angiogenesis. Nature 386, 671-674

[2] Carmeliet, P., and Jain, R. K. (2000) Angiogenesis in cancer and other diseases. Nature 407, 249-257

[3] Yancopoulos, G. D., Davis, S., Gale, N. W., Rudge, J. S., Wiegand, S. J., and Holash, J. (2000) Vascular-specific growth factors and blood vessel formation. Nature 407, 242-248

[4] Hynes, R. O., Bader, B. L., and Hodivala-Dilke, K. (1999) Integrins in vascular development. Braz. J. Med. Biol. Res. $32,501-510$

[5] Ferrara, N. (1999) Vascular endothelial growth factor: molecular and biological aspects. Curr.Top.Microbiol.Immunol.237, 1-30

[6] Dvorak, H. F., Nagy, J. A., Feng, D., Brown, L. F., and Dvorak, A. M. (1999) Vascular permeability factor/vascular endothelial growth factor and the significance of microvascular hyperpermeability in angiogenesis. Curr.Top.Microbiol.Immunol.237, 97-132

[7] Brooks, P. C., Clark, R. A., and Cheresh, D. A. (1994) Requirement of vascular integrin alpha $\mathrm{v}$ beta 3 for angiogenesis. Science 264, 569-571

[8] Hood JD, Cheresh DA. Role of integrins in cell invasion and migration.Nat Rev Cancer 2002; 2: 91-100

[9] Hwang R, Varner J. The role of integrins in tumor angiogenesis.HematolOncolClin North Am 2004; 18: 9911006, vii

[10] ContiJA, Kendall TJ, Bateman A, et al. The desmoplastic reaction surrounding hepatic colorectal adenocarcinoma metastases aids tumour growth and survival via avintegrinligation.ClinCancerRes2008;14:6405^13.

[11] Astler V. B. and Coller F. A., 1954. The prognostic significance of direct extension of carcinoma of the colon and rectum. Ann Surg, 139: 846-847.

[12] Reynolds AR, Reynolds LE, Nagel TE, Lively JC, Robinson SD, Hicklin DJ, Bodary SC, Hodivala-Dilke KM. Elevated Flk1 (vascular endothelial growth factor receptor 2) signaling mediates enhanced angiogenesis in beta3-integrindeficient mice. Cancer Res 2004; 64: 8643-8650

[13] Laakkonen P, Waltari M, Holopainen T, Takahashi T, Pytowski B, Steiner P, Hicklin D, Persaud K, Tonra JR, Witte L, Alitalo K. Vascular endothelial growth factor receptor 3 is involved in tumor angiogenesis and growth. Cancer Res 2007; 67: 593-599

[14] Des Guetz G, Uzzan B, Nicolas P, et al. Microvessel density and VEGF expression are prognostic factors in colorectal cancer. Meta-analysis of the literature. Br J Cancer 2006; 94: 1823-32.

[15] Liang JF, Wang HK, Xiao H, Li N, Cheng CX, Zhao YZ, Ma YB, Gao JZ, Bai RB, Zheng HX. Relationship and prognostic significance of SPARC and VEGF protein expression in colon cancer. JExp Clin Cancer Res 2010;29:71 
[16] Levy N.S, Goldberg-cohen I, and Levy A.P., 2004. Hypoxic regulation of VEGF.VEGF in Colon Cancer.VEGF and Cancer, chapter eight.Edited by Judith H. Harmey.

[17] Guba M, Seeliger H, Karl-Walter Jauch K.W and Bruns C.J., 2004. VEGF in Colon Cancer.VEGF and Cancer, chapter eight.Edited by Judith H. Harmey.

[18] 18.Trikha, M., Timar, J., Zacharek, A., Nemeth, J. A., Cai, Y., Dome, B., Somlai, B., Raso, E., Ladanyi, A., Honn, K. V. (2002) Role for $\beta 3$ integrins in human melanoma growth and survival. Int. J. Cancer 101, 156-167.

[19] Mizejewski GJ. Role of integrins in cancer: survey of expression patterns. ProcSoc ExpBiol Med 1999; 222: 124138

[20] Risau W. Mechanisms of angiogenesis. Nature 1997; 386: 671-674

[21] Cooper CR, Chay CH, Pienta KJ. The role of alpha(v)beta(3) in prostate cancer progression. Neoplasia2002; 4: 191-194

[22] 22.ReinmuthN, Liu W, Ahmad SA, Fan F, Stoeltzing O, Parikh AA, Bucana CD, Gallick GE, Nickols MA, Westlin
WF, Ellis LM. Alphavbeta3 integrin antagonist S247 decreases colon cancer metastasis and angiogenesis and improves survival inmice. Cancer Res 2003; 63: 2079-2087

[23] Stupack, D. G., Puente, X. S., Boutsaboualoy, S., Storgard, C. M., and Cheresh, D. A.(2001) Apoptosis of adherent cells by recruitment of caspase- 8 to unligated integrins. $J$. Cell Biol. 155, 459-470

[24] Vlahakis NE, Young BA, Atakilit A, Hawkridge AE, Issaka $\mathrm{RB}$, Boudreau N,et al. Integrin $\alpha 9 \beta 1$ directly binds to vascular endothelial growth factor (VEGF)-A and contributes to VEGF-A-induced angiogenesis. J BiolChem 2007;282:15187-96.

[25] Hutchings H, Ortega N, Plouët J. Extracellular matrix-bound vascular endothelialgrowth factor promotes endothelial cell adhesion, migration, and survivalthrough integrin ligation. FASEB J 2003;11:1520-2.

[26] Soldi R, Mitola S, Strasly M, Defilippi P, Tarone G, Bussolino $F$. Role of $\alpha v \beta 3$ integrin in the activation of vascular endothelial growth factor receptor-2.EMBO $\mathrm{J}$ 1999;8:882-92. 